\title{
Visualization of cholesterol deposits in lysosomes of Niemann-Pick type C fibroblasts using recombinant perfringolysin $\mathrm{O}$
}

Katarzyna Kwiatkowska', Ewelina Marszałek-Sadowska', Gabriela Traczyk¹, Piotr Koprowski , Małgorzata Musielak², Agnieszka Ługowska², Magdalena Kulma ${ }^{3}$, Anna Grzelczyk and Andrzej Sobota ${ }^{1 *}$

\begin{abstract}
Background: Niemann-Pick disease type C (NPC) is caused by defects in cholesterol efflux from lysosomes due to mutations of genes coding for NPC1 and NPC2 proteins. As a result, massive accumulation of unesterified cholesterol in late endosomes/lysosomes is observed. At the level of the organism these cholesterol metabolism disorders are manifested by progressive neurodegeneration and hepatosplenomegaly. Until now filipin staining of cholesterol deposits in cells has been widely used for NPC diagnostics. In this report we present an alternative method for cholesterol visualization and estimation using a cholesterol-binding bacterial toxin, perfringolysin $\mathrm{O}$.

Methods: To detect cholesterol deposits, a recombinant probe, perfringolysin $\mathrm{O}$ fused with glutathione S-transferase (GST-PFO) was prepared. GST-PFO followed by labeled antibodies or streptavidin was applied for immunofluorescence and immunoelectron microscopy to analyze cholesterol distribution in cells derived from NPC patients. The identity of GST-PFO-positive structures was revealed by a quantitative analysis of their colocalization with several organelle markers. Cellular ELISA using GST-PFO was developed to estimate the level of unesterified cholesterol in NPC cells.

Results: GST-PFO recognized cholesterol with high sensitivity and selectivity, as demonstrated by a protein/lipid overlay assay and surface plasmon resonance analysis. When applied to stain NPC cells, GST-PFO decorated abundant deposits of cholesterol in intracellular vesicles that colocalized with filipin-positive structures. These cholesterol deposits were resistant to $0.05 \%-0.2 \%$ Triton X-100 used for cells permeabilization in the staining procedure. GST-PFO-stained organelles were identified as late endosomes/lysosomes based on their colocalization with LAMP-1 and lysobisphosphatidic acid. On the other hand, GST-PFO did not colocalize with markers of the Golgi apparatus, endoplasmic reticulum, peroxisomes or with actin filaments. Only negligible GST-PFO staining was seen in fibroblasts of healthy individuals. When applied to cellular ELISA, GST-PFO followed by anti-GST-peroxidase allowed a semiquantitative analysis of cholesterol level in cells of NPC patients. Binding of GST-PFO to NPC cells was nearly abolished after extraction of cholesterol with methyl- $\beta$-cyclodextrin.
\end{abstract}

Conclusions: Our data indicate that a recombinant protein GST-PFO can be used to detect cholesterol accumulated in NPC cells by immunofluorescence and cellular ELISA. GST-PFO can be a convenient and reliable probe for revealing cholesterol deposits in cells and can be useful in diagnostics of NPC disease.

Keywords: Niemann-Pick C disease, Lipid storage diseases, Cholesterol-binding proteins, Filipin, Perfringolysin O

\footnotetext{
*Correspondence: a.sobota@nencki.gov.pl

${ }^{1}$ Department of Cell Biology, Nencki Institute of Experimental Biology, 3

Pasteur St., 02-093 Warsaw, Poland

Full list of author information is available at the end of the article
}

\section{Biomed Central}

(c) 2014 Kwiatkowska et al.; licensee BioMed Central Ltd. This is an Open Access article distributed under the terms of the Creative Commons Attribution License (http://creativecommons.org/licenses/by/2.0), which permits unrestricted use, distribution, and reproduction in any medium, provided the original work is properly credited. The Creative Commons Public Domain Dedication waiver (http://creativecommons.org/publicdomain/zero/1.0/) applies to the data made available in this article, unless otherwise stated. 


\section{Background}

Niemann-Pick disease type C (NPC) is a lysosomal storage disorder caused by accumulation of unesterified cholesterol in cells of the brain, liver, etc., that occurs with an estimated frequency of 1 in 120000 individuals [1-4]. This value can be underestimated, since atypical phenotypes may not be properly diagnosed [4]. Cholesterol is internalized by cells from serum mainly as a constituent of low density lipoprotein (LDL) by clathrinmediated endocytosis. The LDL is directed to lysosomes where it is hydrolyzed and free unesterified cholesterol is released [5]. The cholesterol is transported from lysosomes to the plasma membrane and the endoplasmic reticulum where it undergoes esterification. Simultaneously, de novo synthesis of cholesterol and LDL uptake are down-regulated $[2,6,7]$.

The NPC disease is caused by mutations of NPC1 or NPC2 genes coding for lysosomal proteins - NPC1 and NPC2. About $95 \%$ of NPC cases are linked to mutations in the NPC1 gene $[8,9]$. NPC1 is a transmembrane lysosomal protein while NPC2 is localized in the lumen of lysosomes $[10,11]$. The NPC1 and NPC2 proteins are engaged in transporting free cholesterol and some accompanying glycolipids from lysosomes to other cellular compartments $[6,12,13]$. In addition to cholesterol accumulation in lysosomes its synthesis and metabolism are also affected leading to disturbances in the synthesis of steroid hormones and in the assembly of cellular membranes. Predominant symptoms of NPC disease are progressive neurodegeneration and hepatosplenomegaly. The severity of symptoms of NPC disease varies, but typically the disease leads to death in the second decade of life $[3,14]$. The neuropathological lesions in NPC patients can be reduced by application of an inhibitor of glucosylceramide synthase, the main enzyme involved in glycosphingolipid synthesis [15].

Presently, detection of NPC disease requires skin biopsy, cultivation of fibroblasts and their staining with filipin, a fluorescent polyene antibiotic which binds free cholesterol $[3,16]$. However, this approach requires UV excitation and filipin fluorescence is prone to photobleaching, which constrains its application in NPC diagnostics $[17,18]$. Other methods of NPC diagnosis are also considered [19]. Recently, a new approach for detection of NPC disease based on LC-MS/MS analysis of oxidized forms of cholesterol in the serum has been proposed [20], but a wider application of this sensitive and specific method is limited by the availability of the sophisticated equipment.

Alternative visualization of cholesterol deposits in NPC cells could in principle be also based on the application of protein toxins of microbial origin which specifically recognize free cholesterol and can be used as probes for cell staining without the drawbacks of filipin.
About twenty toxins produced by Gram-positive bacteria belong to the family of cholesterol-binding cytolysins [21,22]. Among such bacterial toxins special attention has been paid to perfringolysin $\mathrm{O}$ (PFO) produced by Clostridium perfringens [23,24]. PFO oligomerizes upon binding to membrane cholesterol and leads to pore formation provided the cholesterol content exceeds 30 mol\% $[25,26]$. A biotinylated proteolytic derivative of PFO, named BC $\theta$, of molecular mass of $57 \mathrm{kDa}$, has been used to stain NPC cells. In those studies, cells were fixed with $4 \%$ paraformaldehyde and exposed to $\mathrm{BC} \theta$ without cellular membrane permeabilization, yielding intracellular staining $[27,28]$. Taking into account the relatively high molecular mass of $\mathrm{BC} \theta$, the mechanism of its entry into cells and the nature of "the cholesterol-rich domains" detected by BC $\theta$ [27] remain unknown.

In this study we prepared PFO fused with glutathione $\mathrm{S}$-transferase (GST) and used the recombinant protein to detect cholesterol-rich organelles in Triton X-100permeabilized NPC and healthy-donor cells. The GSTPFO-positive vesicles, found only in NPC cells, also stained with filipin, antibodies against lysosomal-associated membrane protein 1 (LAMP-1) and lysobisphosphatidic acid (LBPA), indicating that the procedure detected accumulation of cholesterol in late endosomes/lysosomes in NPC cells.

\section{Methods}

\section{Fibroblast cultures}

The studies were performed on fibroblasts derived from NPC patients and from healthy donors. The NPC patients had been diagnosed on the basis of clinical, cytochemical (Department of Genetics, Institute of Psychiatry and Neurology, Warsaw, Poland) and/or molecular parameters (NZOZ Genomed, Warsaw, Poland). To obtain fibroblast cultures, skin biopsies were dissected and cells were grown for up to 7 passages in DMEM medium containing $10 \% \mathrm{FBS}, 50 \mathrm{U} / \mathrm{ml}$ penicillin, $50 \mu \mathrm{g} / \mathrm{ml}$ streptomycin, $0.2 \mu \mathrm{g} / \mathrm{ml}$ amphotericin $\mathrm{B}$ at $37^{\circ} \mathrm{C}, 5 \% \mathrm{CO}_{2}$. Prior to experiments cells were transferred to DMEM medium with delipidated 10\% FBS and cultured for $72 \mathrm{~h}$ [29]. The delipidated FBS was prepared according to Cham and Knowles [30] using organic solvents (di-isopropyl ether and n-butanol, 40:60, v:v) and filtered throughout a $0.22 \mu \mathrm{m}$ sterile filter. The procedure removed $96 \%$ of the original cholesterol content in FBS, as determined by the Cholesterol DST kit (Alpha Diagnostics). This study was conducted in accordance with the Helsinki Declaration. Ethical approval of the study was requested at the local Bioethical Committee of the Institute of Psychiatry and Neurology in Warsaw, Poland. According to the information obtained from the Committee, the usage of biological material taken from patients, which was excessive after diagnostics procedures, does not demand a special 
approval on the condition that patients signed an informed consent for such action. Patients gave their signed informed consent for the use of their cells in the scientific experiments after anonimization of the material samples.

For cholesterol depletion, cells cultured in medium containing delipidated 10\% FBS were fixed, permeabilized as described further, and exposed for $1 \mathrm{~h}$ to $3 \mathrm{mM}$ methyl- $\beta$-cyclodextrin (Sigma) in PBS at $37^{\circ} \mathrm{C}$. To trigger uptake of LDL, cells were cultured in the presence of delipidated 10\% FBS (72 h) and subsequently incubated with $10 \mu \mathrm{g} / \mathrm{ml}$ DiI-LDL (Biomed. Technology) in DMEM/ delipidated $10 \%$ FBS for $5 \mathrm{~h}$ at $37^{\circ} \mathrm{C}$.

\section{Preparation of recombinant PFO}

A synthetic gene for perfringolysin $\mathrm{O}$ of Clostridium perfringens was prepared by GenScript (USA) basing on cDNA sequence No. CP000246.1 at NCBI. The sequence was optimized for expression in $E$. coli. The synthesized gene was devoid of a leader sequence coding for $28 \mathrm{~N}$-terminal amino acids to ensure intracellular accumulation of the expressed protein. The product was cloned by the vendor into pUC57 plasmid. To obtain PFO with a GST tag at the N-terminus, the construct was cloned into pGEX4T vector using BamHI and EcoRI sites. To allow potential removal of the GST tag, the construct was modified by introducing the sequence 5' GAA AAC CTG TAT TTT CAG GGC 3' encoding the ENLYFQG motif recognized by Tobacco Etch Virus (TEV) protease [31].

The recombinant vector was transformed into $\mathrm{BL}-21$ (DE3) strain of E. coli. Bacteria were grown at $37^{\circ} \mathrm{C}$ in LB medium containing $100 \mu \mathrm{g} / \mathrm{ml}$ ampicillin to $\mathrm{OD}=$ 0.6 , when $0.5 \mathrm{mM}$ IPTG was added. The culture was continued at $18^{\circ} \mathrm{C}$ for $20 \mathrm{~h}$, bacteria were harvested, washed in PBS and lysed in the presence of $0.35 \mathrm{mg} / \mathrm{ml}$ lysozyme $\left(10 \mathrm{~min}, 4^{\circ} \mathrm{C}\right.$ ). The obtained suspension was supplemented with $1 \%$ Triton X-100 and sonicated on ice for $15 \mathrm{~min}$ at 0.3 cycle, amplitude 33\%, using an UP200S Hielscher sonifier (Germany). The lysate was clarified by centrifugation at $20000 \times \mathrm{g}$ for $40 \mathrm{~min}$ at $4^{\circ} \mathrm{C}$ and loaded onto a Glutathione-Sepharose 4B column (bioWORLD). GST-PFO was eluted from the column with $10 \mathrm{mM}$ glutathione, $10 \mathrm{mM}$ DTT, $50 \mathrm{mM}$ Tris, $\mathrm{pH}$ 8.0. The GST protein was prepared as described earlier [32]. The presence and purity of the recombinant proteins in column fractions were examined by $10 \%$ SDS-PAGE. Fractions containing highest amounts of GST-PFO or GST were pooled and filtered over Amicon Ultra-15 centrifugal filter units to remove glutathione and concentrate the protein. Samples containing about $0.45 \mathrm{mg} / \mathrm{ml}$ GSTPFO or $0.6 \mathrm{mg} / \mathrm{ml} \mathrm{GST}$ in $5 \mathrm{mM}$ DTT, $50 \mathrm{mM}$ Tris, $\mathrm{pH} 8.0$ were supplemented with $20 \%$ sucrose and frozen in liquid nitrogen.

\section{Protein-lipid overlay assay}

The analysis was performed essentially as described earlier [33] with modifications. The following lipids were used: semisynthetic bovine brain sphingomyelin (SM), C16-ceramide, cholesterol, dioleoylphosphatidylcholine (DOPC), dipalmitoylphosphatidylcholine (DPPC) and dipalmitoylphosphatidylethanolamine (DPPE) (all from Sigma). The lipids were dissolved in chloroform:methanol: $\mathrm{H}_{2} \mathrm{O}(1: 1: 0.3)$ and $1 \mu \mathrm{l}$ of the solution containing 25-500 pmoles of lipid was spotted onto a $0.45-\mu \mathrm{m}$ nitrocellulose membrane. The membrane was pressed with a hot block at $60^{\circ} \mathrm{C}$ for $5 \mathrm{~s}$ according to Taki and Ishikawa [34], blocked with $1 \%$ gelatin and $1 \%$ polyvinylpyrrolidone and incubated for $45 \mathrm{~min}$ at $20^{\circ} \mathrm{C}$ with $1 \mu \mathrm{g} / \mathrm{ml}$ GST-PFO in PBS buffer containing 0.03\% Tween-20. After washing, the membrane was exposed for $45 \mathrm{~min}$ to chicken antiGST IgY-peroxidase (Rockland). Immunoreactive spots were visualized with the SuperSignal West Pico chemiluminescence substrate (Pierce).

\section{Carboxyfluorescein release from liposomes}

Liposomes composed of (i) cholesterol:SM:DOPC (mol\% 40:30:30), (ii) cholesterol:DPPE:DOPC (mol\% 40:30:30), (iii) SM:DPPC:DOPC (mol\% 40:30:30) or (iv) DPPE: DPPC:DOPC (mol\% 40:30:30) loaded with $10 \mathrm{mM}$ 6carboxyfluorescein were prepared as described earlier [32] with modifications. Lipids were mixed, dried under nitrogen, resuspended in PBS containing $10 \mathrm{mM}$ 6carboxyfluorescein and sonicated in nitrogen atmosphere (15 min, $4^{\circ} \mathrm{C}, 0.3$ cycle with amplitude $33 \%$ in the UP200S Hielscher sonifier). Pelleted liposomes $(2000 \times \mathrm{g}, 10 \mathrm{~min})$ were resuspended in PBS at a total concentration of lipids of $1 \mathrm{mM}$. Release of 6-carboxyfluorescein from the liposomes was induced by $15 \mu \mathrm{g} / \mathrm{ml}$ GST-PFO and measured at $\mathrm{Em} / \mathrm{Ex}=490 / 520 \mathrm{~nm}$ on a Spex spectrofluorimeter (Jobin-Yvone). The maximal efflux of 6-carboxyfluorescein was determined in the presence of $0.2 \%$ Triton X-100.

\section{Surface plasmon resonance (SPR)}

The analysis was performed on large unilamellar vesicles, $100 \mathrm{~nm}$ in diameter, containing cholesterol:DOPC, DPPE:DPPC or SM:DPPC (mol\% 50:50) and prepared as described by Kulma et al. [32]. The liposomes were deposited on the L1 chip of a BIACore X apparatus (BIACore, GE Healthcare) at a flow rate of $1 \mu \mathrm{l} / \mathrm{min}$ for $10 \mathrm{~min}$. Binding experiments were performed at $10 \mu \mathrm{g} / \mathrm{ml}$ GSTPFO or $10-60 \mu \mathrm{g} / \mathrm{ml}$ GST in $150 \mathrm{mM} \mathrm{NaCl}, 30 \mathrm{mM}$ Tris, $\mathrm{pH}$ 8.0, at a flow rate of $30 \mu \mathrm{l} / \mathrm{min}$. After $10 \mathrm{~min}$ (binding phase) the samples were washed for another $10 \mathrm{~min}$ (dissociation phase).

\section{Determination of total cellular cholesterol}

Cells, $3 \times 10^{6} /$ sample, were scraped from dishes after $72 \mathrm{~h}$ of culturing in DMEM/delipidated 10\% FBS, washed 
twice with PBS, suspended in $200 \mu \mathrm{l}$ of hexane:isopropanol (3:2, v:v), sonicated and incubated for $15 \mathrm{~min}$ at $20^{\circ} \mathrm{C}$ with shaking. Extracted lipids were dried under $\mathrm{N}_{2}$ and resuspended in $50 \mu \mathrm{l}$ isopropanol $\left(45 \mathrm{~min}, 20^{\circ} \mathrm{C}\right.$ ). Aliquots of $30 \mu \mathrm{l}$ were mixed with $300 \mu \mathrm{l}$ of Cholesterol DST reagent and processed according to the manufacturer's instructions (Alpha Diagnostics). Protein content in "cell skeletons" remaining after lipid extraction was estimated by Bradford Ultra reagent (Expedeon Ltd) and measured at $595 \mathrm{~nm}$.

\section{Determination of chitotriosidase activity}

The enzyme activity was measured in samples of blood serum using 4-methylumbelliferyl- $\beta-\mathrm{D}-N, N, N$ '-triacetylchitotriose as a substrate (Sigma) according to [35].

\section{Cellular ELISA}

Cells were seeded in DMEM/10\% FBS on 96-well plates at $5 \times 10^{3}$ cells/well, unless indicated otherwise. After $8 \mathrm{~h}$, the medium was replaced with DMEM/delipidated $10 \%$ FBS and the cultures were grown for $72 \mathrm{~h}$. Then, the cells were washed, fixed in $3 \%$ paraformaldehyde in PHEM buffer (60 mM PIPES, $25 \mathrm{mM}$ HEPES, $10 \mathrm{mM}$ EGTA, $4 \mathrm{mM} \mathrm{MgCl}_{2}$, pH 6.9), washed in PBS buffer, exposed to $50 \mathrm{mM} \mathrm{NH}{ }_{4} \mathrm{Cl} / \mathrm{PBS}\left(5 \mathrm{~min}, 20^{\circ} \mathrm{C}\right.$ ), washed again and permeabilized with $0.05 \%$ Triton X-100/PBS for $10 \mathrm{~min}$ at $20^{\circ} \mathrm{C}$. In a series of experiments cells were permeabilized with $0.03-0.2 \%$ Triton X-100 (10 min, $20^{\circ} \mathrm{C}$ ) or $0.05 \%$ digitonin $\left(10 \mathrm{~min}, 20^{\circ} \mathrm{C}\right)$. The detergent was washed out with PBS and the cells were incubated for $45 \mathrm{~min}$ at $20^{\circ} \mathrm{C}$ in $3 \%$ fish gelatin/PBS followed by $5 \mu \mathrm{g} / \mathrm{ml}$ GST-PFO in PBS buffer containing 1\% fish gelatin (Sigma). When indicated, prior to labeling with GST-PFO cells were incubated with $3 \mathrm{mM}$ methyl- $\beta$ cyclodextrin for $60 \mathrm{~min}$ at $37^{\circ} \mathrm{C}$. After washing 5 times in $1 \%$ fish gelatin/PBS, the cells were incubated with $2 \mu \mathrm{g} / \mathrm{ml}$ chicken anti-GST IgY-peroxidase in 1\% fish gelatin/PBS (45 min, $20^{\circ} \mathrm{C}$ ), washed 3 times in $1 \%$ fish gelatin/PBS and 3 times in PBS alone. The enzymatic activity of bound peroxidase was examined in the presence of $0.05 \mathrm{mg} / \mathrm{ml}$ $3,3^{\prime}, 5,5^{\prime}$-tetramethylbenzidine and $0.045 \% \mathrm{H}_{2} \mathrm{O}_{2}$. After $30 \mathrm{~min}$, the reaction was stopped with $1 \mathrm{M} \mathrm{H}_{2} \mathrm{SO}_{4}$ and the absorbance was measured at $450 \mathrm{~nm}$ using a Sunrise Plate Reader (Tecan Group). The results were normalized against protein content in samples estimated by Bradford Ultra at $595 \mathrm{~nm}$. Samples were run in parallel with and without treatment with GST-PFO. The values of 450/595 absorbance obtained in samples not-treated with GSTPFO were subtracted from the corresponding values of samples incubated with GST-PFO.

\section{Immunofluorescence studies}

Cells $\left(1 \times 10^{4} /\right.$ sample $)$ were seeded on coverslips $(15 \times 15$ $\mathrm{mm}$ ) in DMEM containing 10\% FBS and after $18 \mathrm{~h}$ the medium was replaced with DMEM supplemented with delipidated 10\% FBS and cultured for $72 \mathrm{~h}$. Cells were washed with PBS, fixed with $3 \%$ paraformaldehyde in PHEM buffer $\left(30 \mathrm{~min}, 20^{\circ} \mathrm{C}\right.$ ) and processed essentially as described [36]. Briefly, cells were washed, incubated with $50 \mathrm{mM} \mathrm{NH} \mathrm{mH}_{4} \mathrm{Cl} / \mathrm{PBS}$ for $5 \mathrm{~min}$ at $20^{\circ} \mathrm{C}$ and permeabilized with $0.05 \%$ Triton $\mathrm{X}-100 / \mathrm{PBS}$ for $10 \mathrm{~min}$ at $4^{\circ} \mathrm{C}$. Alternatively, in a series of experiments cells were permeabilized with $0.05 \%$ digitonin/PBS for $10 \mathrm{~min}$ at $20^{\circ} \mathrm{C}$. After washing in PBS, cells were incubated twice with $3 \%$ fish gelatin in PBS (30 min each incubation). Next, cells were treated with $5 \mu \mathrm{g} / \mathrm{ml} \mathrm{GST-PFO} \mathrm{for}$ $45 \mathrm{~min}$ at $20^{\circ} \mathrm{C}$ and washed five times in $0.2 \%$ fish gelatin/PBS. To detect the probe, the cells were exposed to goat IgG anti-GST conjugated with biotin (Rockland) prepared in $0.2 \%$ fish gelatin/PBS $\left(45 \mathrm{~min}, 20^{\circ} \mathrm{C}\right)$. In studies on colocalization of PFO-stained structures, the anti-GST antibody was accompanied by: (i) rabbit antiLAMP-1 IgG (Santa Cruz Biotechnology), (ii) rabbit anti-golgin-84 IgG (Santa Cruz Biotechnology), (iii) rabbit anti-protein disulfide isomerase (PDI; Cell Signaling), (iv) mouse anti-peroxisomal membrane protein 70 (PMP70) (Sigma), (v) mouse anti-LBPA IgG (clone 6C4; Echelon), or (vi) phalloidin-FITC (Sigma). Unbound antibodies and phalloidin were washed out five times with $0.2 \%$ fish gelatin/PBS and the samples were incubated for $45 \mathrm{~min}$ at $20^{\circ} \mathrm{C}$ either with streptavidin-TRITC (Sigma) and goat anti-rabbit IgG $\mathrm{F}(\mathrm{ab})_{2}$-FITC (Jackson ImmunoResearch) or goat anti-mouse IgG-FITC (ICN). In some experiments cells were exposed to $25 \mu \mathrm{g} / \mathrm{ml}$ filipin III (Sigma) for $45 \mathrm{~min}$ at $20^{\circ} \mathrm{C}$ in darkness and GSTPFO was detected using goat IgG anti-GST followed by donkey anti-goat-Texas Red (Jackson Immunoresearch). When living cells were exposed to $10 \mu \mathrm{g} / \mathrm{ml}$ DiI-LDL, they were washed after $5 \mathrm{~h}$ at $37^{\circ} \mathrm{C}$, fixed with $3 \%$ paraformaldehyde, permeabilized with $0.05 \%$ Triton X-100, incubated with $5 \mu \mathrm{g} / \mathrm{ml}$ GST-PFO followed by the antiGST-biotin antibody, as described above and exposed to streptavidin-FITC (45 min, $20^{\circ} \mathrm{C}$; Sigma). After extensive washing in $0.2 \%$ fish gelatin/PBS, samples were mounted in mowiol/DABCO and examined either under a Nikon microscope equipped with a DXM1200C digital camera or under a Leica confocal microscope (TCS SP8 SMD). TRITC and FITC, TRITC and filipin, DiI-LDL and FITC were excited in the mode of sequential excitation to exclude cross-over of their fluorescence. Stacks of 8-10 confocal planes were acquired for each analyzed cell. The setting of photomultipliers were adjusted to obtain comparable ranges of pixel intensity in each channel, scan resolution was $1024 \times 1024$. Colocalization analysis was performed on single-plane confocal images using Leica Application Suite AF software which calculated the Perason's correlation coefficient and the overlap coefficient [32]. For both signals the intensity threshold 
value was set at $55 \%$ and $20 \%$ background subtraction was applied. At least 20 cells from two independent experiments were analyzed for each variant.

\section{Electron microscopy}

For the studies, NPC and control healthy fibroblasts were grown in 10-cm Petri dishes to confluence and after washing with PBS, were fixed with $3 \%$ formaldehyde $/ 0.5 \%$ glutaraldehyde in $100 \mathrm{mM}$ sodium phosphate buffer $\left(\mathrm{pH} \mathrm{7.2)}\right.$ for $30 \mathrm{~min}$ at $20^{\circ} \mathrm{C}$. Cells were washed twice with the phosphate buffer, treated with $50 \mathrm{mM}$ $\mathrm{NH}_{4} \mathrm{Cl}$ in the buffer $\left(10 \mathrm{~min}, 20^{\circ} \mathrm{C}\right)$, washed and gently scraped off the dishes. Pelleted cells $(2000 \times \mathrm{g}, 2.5 \mathrm{~min})$ were dehydrated in an ethanol series $\left(20^{\circ} \mathrm{C}\right)$ followed by incubations in mixtures of LR White resin/ethanol at ratios 1:1, 2:1 and 3:1, each for $1 \mathrm{~h}$. Finally, the samples were infiltrated with $100 \%$ LR White overnight, after which the resin was exchanged twice $\left(1 \mathrm{~h}, 20^{\circ} \mathrm{C}\right)$. The samples were polymerized at $56^{\circ} \mathrm{C}$ for $48 \mathrm{~h}$. Ultrathin sections were placed on formvar-coated nickel grids and blocked with $3 \%$ fish gelatin in PBS and next in a mixture of $3 \%$ BSA and 1\% polyvinylpyrrolidone in PBS (50 min each incubation). Subsequently, the samples were incubated overnight with $10 \mu \mathrm{g} / \mathrm{ml}$ GST-PFO and rabbit anti-LAMP-1 antibody in $0.2 \%$ fish gelatin/PBS in a humid atmosphere. After washing five times with $0.2 \%$ fish gelatin $/ 0.05 \%$ Tween-20/PBS, the samples were incubated with goat anti-GST IgG-biotin $(3.5 \mathrm{~h})$ and after washing, exposed to goat anti-biotin IgG conjugated with $6 \mathrm{~nm}$ gold particles and donkey anti-rabbit IgG$10 \mathrm{~nm}$ gold (both Aurion) prepared in $0.2 \%$ fish gelatin/ 0.05\% Tween-20/PBS (3 h). After extensive washing: six times with $0.2 \%$ fish gelatin $/ 0.05 \%$ Tween-20/PBS, thrice with PBS and twice with distilled $\mathrm{H}_{2} \mathrm{O}$, the samples were counterstained with $2.5 \%$ uranyl acetate in $50 \%$ ethanol for $15 \mathrm{~min}$ in dark, washed with $50 \%$ ethanol and distilled $\mathrm{H}_{2} \mathrm{O}$, and stained with lead citrate for $2 \mathrm{~min}$. Finally, the samples were washed with distilled $\mathrm{H}_{2} \mathrm{O}$, dried and examined under a JEM 1400 (Jeol) electron microscope.

\section{Results}

\section{Expression of GST-PFO}

In order to obtain a selective cholesterol-binding probe, a synthetic gene encoding perfringolysin $\mathrm{O}$ was cloned inframe with the GST-encoding sequence in the pGEX4T vector. To preclude secretion of the fusion protein, the PFO sequence was trimmed at the $5^{\prime}$ end by removing the first 28 amino acids comprising a leader peptide. In addition, a heptapeptide motif recognized by TEV protease was introduced between the GST and $28 \triangle \mathrm{PFO}$ sequence allowing potential cleavage of the GST tag. The GST-PFO fusion protein was expressed in E. coli and purified by one-step affinity chromatography on GlutathioneSepharose; the protein migrated as a $78-\mathrm{kDa}$ band on SDS-PAGE and was ca. $98 \%$ pure (not shown).

In this study the uncleaved GST-PFO protein was used as the GST tag was useful for detection of PFO in cells. To assess whether the recombinant GST-PFO protein selectively recognized and bound cholesterol, a proteinlipid overlay assay was performed. The probe at $1 \mu \mathrm{g} / \mathrm{ml}$ detected cholesterol in a dose-dependent manner starting from 25 pmoles of the lipid and with high specificity, as it did not recognize ceramide or phospholipids such as sphingomyelin, DOPC, DPPC and DPPE (Figure 1A).
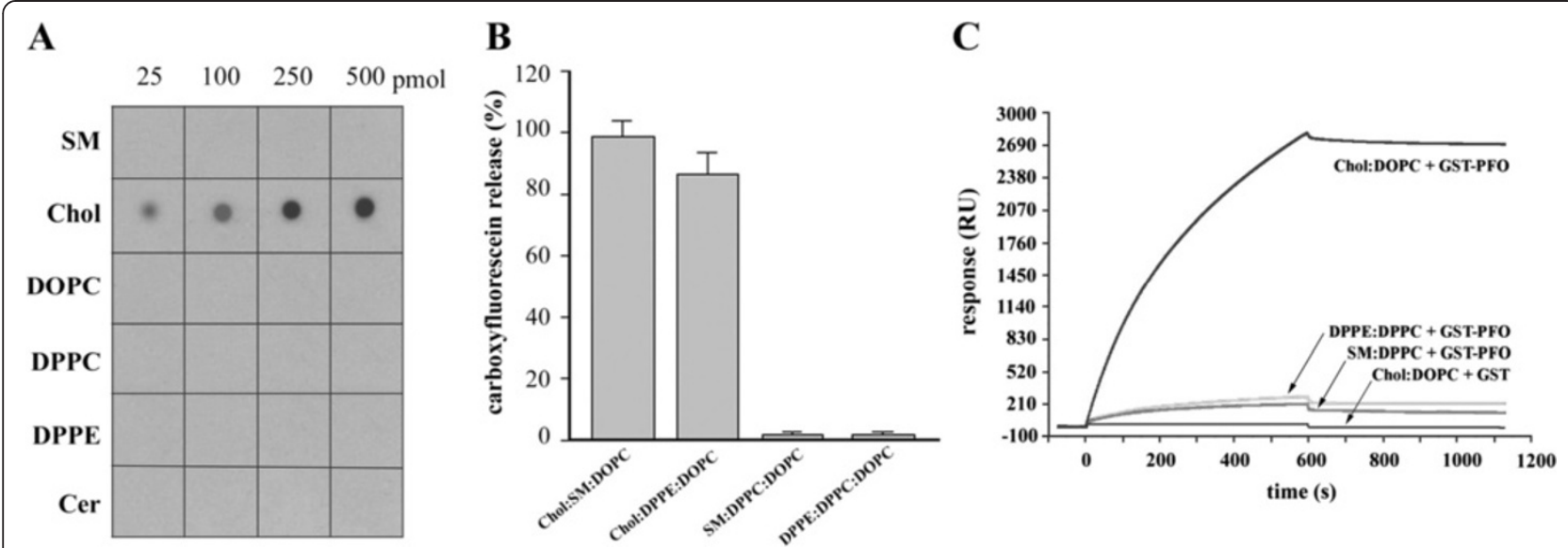

Figure 1 Selective recognition of cholesterol by GST-PFO. (A) Protein-lipid overlay assay. Indicated amounts of lipids were spotted on nitrocellulose membrane and incubated with $1 \mathrm{\mu g} / \mathrm{ml}$ GST-PFO. Immunoreactive spots were revealed by chemiluminescence. (B) 6-Carboxyfluorescein release from liposomes of indicated composition induced by $15 \mu \mathrm{g} / \mathrm{ml}$ GST-PFO. The data are expressed as percentage of the total amount of 6-carboxyfluorescein released from liposomes by $0.2 \%$ Triton X-100. (C) SPR sensograms of binding of $10 \mu \mathrm{g} / \mathrm{ml}$ GST-PFO or $20 \mu \mathrm{gg} / \mathrm{ml}$ GST to liposomes of indicated lipid composition immobilized on the surface of sensor chip L1. Binding of GST-PFO to liposomes was carried out for $600 \mathrm{~s}$ after which the samples were washed for another $600 \mathrm{~s}$. In (A) and (C) data represent one of three independent experiments; in (B) mean \pm SEM from three experiments is shown. Chol - cholesterol; Cer - ceramide; SM - sphingomyelin. 
Upon binding to cholesterol-containing membranes, PFO undergoes oligomerization and forms pores responsible for its lytic activity [37]. We found that GST-PFO displayed lytic activity and released 6-carboxyfluorescein trapped in cholesterol-containing liposomes regardless of the composition of the accompanying phospholipids (Figure 1B). The permeabilizing activity of GST-PFO confirmed the protein's specificity - it did not induce the release of 6-carboxyfluorescein from liposomes devoid of cholesterol (Figure 1B). When incubated with sheep erythrocytes, in which cholesterol constitutes about $30 \%$ of the total lipid content [38], GST-PFO induced maximal hemolysis at $200 \mathrm{ng} / \mathrm{ml}$ (not shown).

Strong binding of GST-PFO to cholesterol-containing liposomes was also revealed by surface plasmon resonance analysis (Figure $1 C$ ). The binding indicated by a resonance value of about $2800 \mathrm{RU}$ was stable during 10 minutes of washing of the samples. There was no binding of GST alone to the liposomes. The binding of GST-PFO to liposomes devoid of cholesterol was negligible (Figure 1C). The data indicate that GST-tagged PFO retained selectivity for cholesterol binding characteristic for native PFO $[25,26]$.

\section{GST-PFO and filipin stain the same organelles}

Filipin staining is a generally accepted tool for detection of cholesterol deposits in NPC cells [3,39-41]. We aimed to characterize PFO as another convenient probe for visualization and analysis of cholesterol in cells. In fibroblasts derived from NPC patients, fixed and permeabilized with $0.05 \%$ Triton-X100, GST-PFO strongly stained the abundant perinucler structures (Figure 2A). After prolonged lipid deprivation, the staining was moderately decreased revealing that the GST-PFO-stained deposits were located in vesicles (Figure 2B). The pattern of cell staining by GST-PFO was similar to that shown by filipin (compare Figure 2A and A, B and B'; typical vesicles with clear colocalization are marked by arrows). However, small vesicles seemed to be decorated more strongly by GST-PFO than by filipin (Figure 2B', inset). The staining of NPC cells with GST-PFO was specific to the probe since only residual labeling was detected when GST-PFO was omitted. Simultaneously, cholesterol deposits were revealed in these cells by filipin (Figure 2C, C'). Only negligible staining with GST-PFO or filipin was found in fibroblasts from healthy individuals (Figures 2D, D'). Together with the selectivity of GSTPFO for cholesterol demonstrated by physico-chemical approaches presented in Figure 1, the fluorescence microscopy data strongly suggest that GST-PFO detects cholesterol stored in NPC cells.

Beside perinuclear cholesterol deposits, GST-PFO probe also detected small vesicles located at the cell periphery which were abundant in NPC cells cultured in a complete medium (Figure 2A). Since these vesicles could correspond to LDL-containing endosomes, NPC cells and fibroblasts from healthy individuals were incubated with $10 \mu \mathrm{g} / \mathrm{ml} \mathrm{DiI-LDL}$ for $5 \mathrm{~h}$, and subsequently subjected to GST-PFO co-staining (Figure 3). Confocal microscopy analysis revealed that in NPC cells, DiI-LDL accumulated in various amounts within perinuclear vesicles co-labeled with GST-PFO (Figure 3A-A"). DiI-LDL was also present in numerous vesicles along an "endocytic track" leading from the cell periphery toward the perinuclear region. These vesicles containing DiI-LDL were decorated with GST-PFO with variable intensity: GST-PFO staining was absent in vesicles at the start of the "endocytic track" and increased gradually toward the cell center (Figure 3A", inset). The presence of free cholesterol in endocytic veiscles can result from disturbances in the lipid distribution in NPC cells or can indicate that in these cells cholesterol deesterification starts already in endosomes. In control fibroblasts, despite intensive LDL endocytosis, no staining of LDL-containing vesicles with GST-PFO was detected (Figure 3B-B”).

\section{The organelles stained by GST-PFO bear markers of late endosomes and lysosomes}

To identify the vesicles stained by GST-PFO in NPC fibroblasts, colocalization of the probe with markers of different cellular compartments was analyzed. Of the several organelle-specific probes, the LAMP-1-specific staining of lysosomes overlapped markedly with the GST-PFO signal (Figure 4A-A"). Magnified confocal optical sections revealed that at the basolateral level, LAMP-1 and GST-PFO signals were rather separated but their colocalization increased in the middle part of the cell (Figure 4A"s1-s4). Individual vesicles displayed partial overlapping of LAMP-1 and GST-PFO staining which changed along the vertical axis (Figure 4A" s1-s4, circles). To estimate the degree of colocalization of GSTPFO and LAMP-1-positive vesicles, a quantitative analysis was performed of dual-color confocal images. Two different values were calculated: the Pearson's correlation coefficient and the overlap coefficient [42]. As seen in Figure 5, the Pearson's correlation coefficient for coimmunostaining of GST-PFO and LAMP was high and reached $0.59 \pm 0.05$ (in relation to 1 as the maximal value). The overlap coefficient of the two fluorescence patterns was also high $(0.64 \pm 0.05)$. We estimated also colocalization of GST-PFO and filipin staining (see Figure 4B-B"). The Pearson's correlation coefficient and the overlap coefficient for fluorescence generated by these two probes were as high as $0.53 \pm 0.03$ and $0.65 \pm 0.02$, respectively (Figure 5).

Previous studies indicated that cholesterol-containing vesicles stained by filipin in NPC cells were rich in LBPA, a marker of late endosomes-multivesicular bodies [43,44]. 

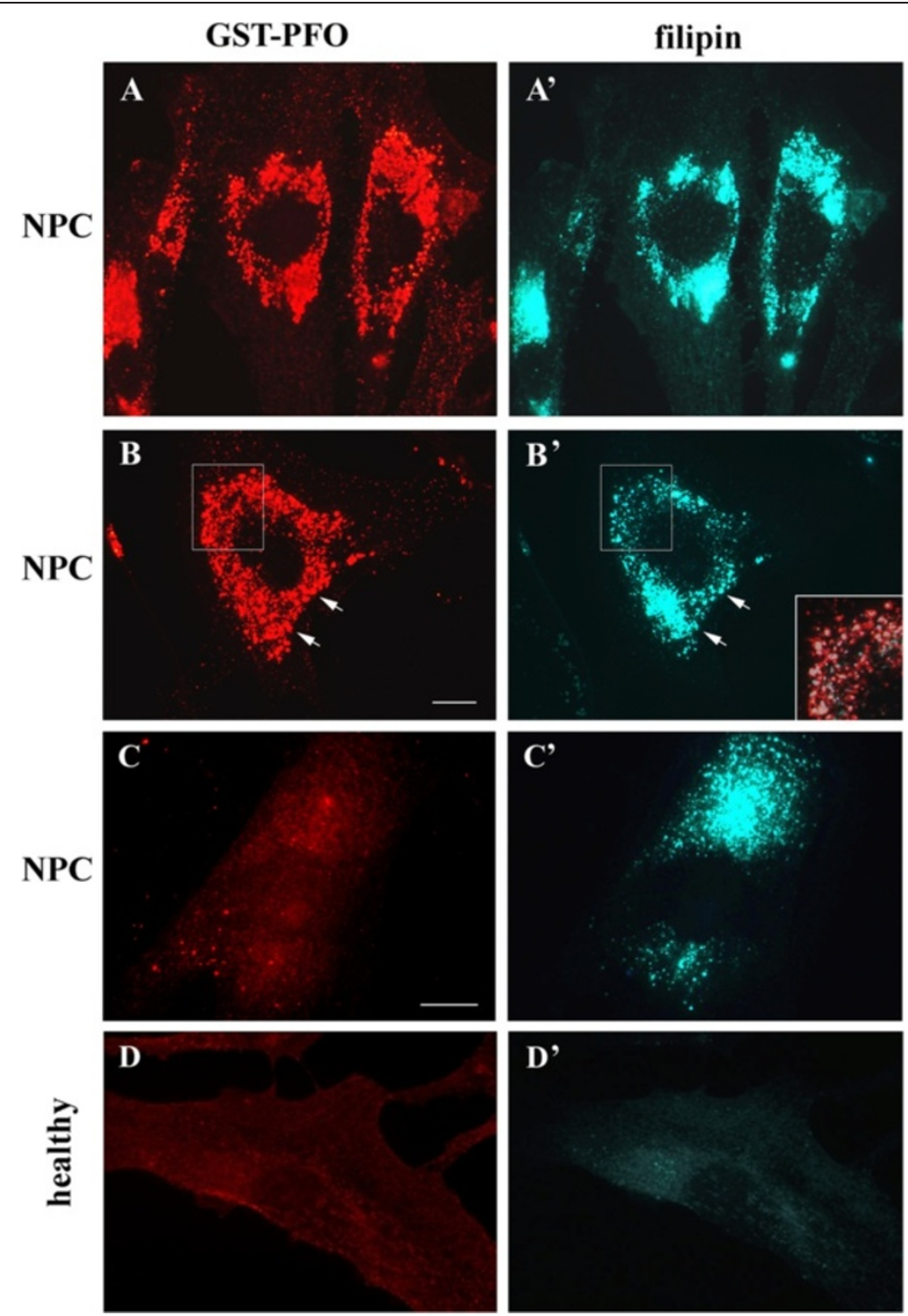

Figure 2 GST-PFO labels cholesterol deposits in NPC fibroblasts. (A-C) NPC fibroblasts were cultured in DMEM/10\% FBS (A, $\left.\mathbf{A}^{\prime}\right)$ or in DMEM

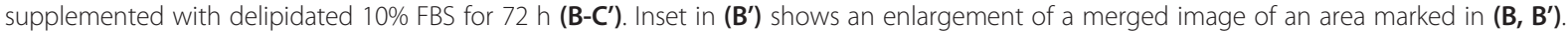
Colocalization of GST-PFO and filipin staining is in white. Colocalization of the labels is also seen in vesicles marked by arrows in (B, $\left.\mathbf{B}^{\prime}\right)$. (C, $\left.\mathbf{C}^{\prime}\right)$ Omitting GST-PFO during labeling of permeabilized NPC cells yields only traces of non-specific staining with secondary antibodies (C). In these conditions, filipin detects cholesterol accumulated in the cells ( $\left.\mathbf{C}^{\prime}\right)$. (D-D') Fibroblasts from a healthy donor were cultured in DMEM/delipidated 10\% FBS. Cells were fixed, permeabilized with $0.05 \%$ Triton X-100 and incubated with $5 \mu \mathrm{g} / \mathrm{ml}$ GST-PFO followed by secondary antibodies conjugated with Texas Red (left) or with $25 \mu \mathrm{g} / \mathrm{ml}$ filipin (right) to compare the staining patterns revealed by the two probes. Scale bar, $20 \mu \mathrm{m}$.

Our attempts to analyze colocalization of GST-PFOlabeled and LBPA-rich structures were, however, strongly impeded by technical conditions of cell staining. Permeabilization of cells with $0.05 \%$ Triton X-100 which was optimal for cholesterol detection (see data below) did not promote visualization of LBPA. In these conditions, only a sub-population of GST-PFO-positive vesicles was labeled with the anti-LPBA antibody (Figure 6A-A"). The Pearson's correlation coefficient and the overlap coefficient for the two lipids reached $0.36 \pm 0.04$ and $0.52 \pm 0.04$, respectively (Figure 5). In accordance, permeabilization of control fibroblast with Triton X-100 did not permit detection of LBPA in these cells (not shown). Application of 0.05\% digitonin for cell permeabilization led to detection of numerous LBPA-bearing endosomes in the control cells (Figure 6C-C"), markedly improved detection of LBPA in NPC cells (Figure 6B-B"), and increased the extent of colocalization of LBPA and GST-PFO staining (Figure 5). It should be noted that treatment of cells with digitonin removed substantial amounts of cholesterol from NPC cells 


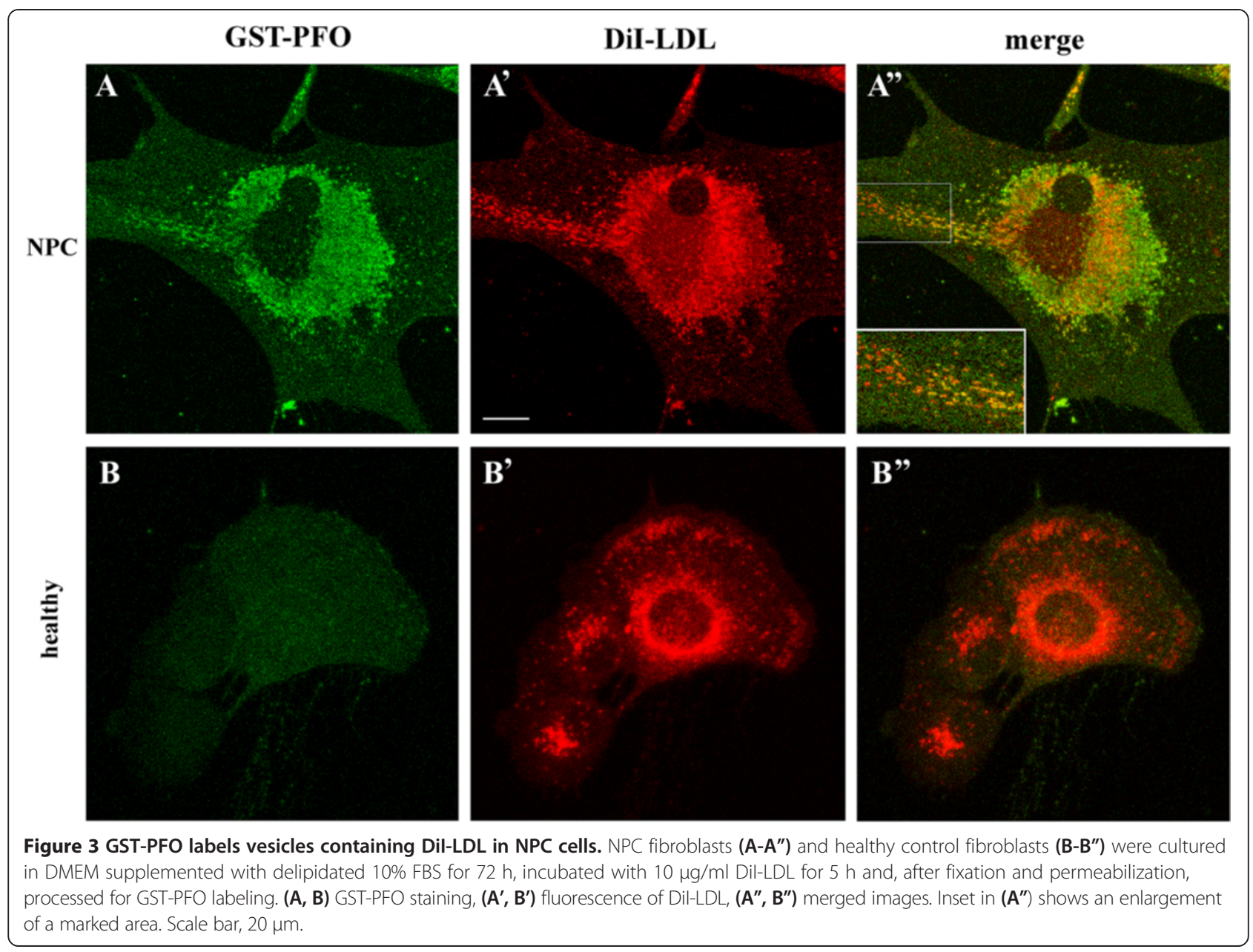

(see data below) and could affect colocalization studies. Taken together, the data suggest that vesicles containing cholesterol deposits detected by GST-PFO also contained LAMP-1 and LBPA, the markers of late endosomes and lysosomes.

In contrast, cis-Golgi cisterns decorated with antigolgin-84 antibody were located only in a close vicinity of the nucleus and could be easily distinguished from the GST-PFO-positive structures (Figure 7A-A"). There were also no similarities between the patterns of staining obtained with GST-PFO and with the anti-PDI antibody which decorated the endoplasmic reticulum (Figure 7B-B"). Moreover, antibodies against PMP70 of peroxisomes and phalloidin-FITC, which labels actin filaments, exhibited unique labeling patterns that were unlike the labeling obtained with GST-PFO (Figure 7C-C" and 7D-D"). The lack of colocalization of GST-PFO-positive vesicles with the indicated organelle markers was reflected by low values of the Pearson's correlation and the overlap coefficients which were in the range of $0.16-0.27$ and $0.21-0.40$, respectively (Figure 5).
Immunoelectron microscopy analysis of NPC cell labeling with GST-PFO

To perform ultrastructural analysis of GST-PFO labeling, NPC cells were embedded in LR White resin. Ultrastructural sections of the cells were processed for post-embedding labeling with GST-PFO and anti-LAMP1 antibody. Figure 8A,B shows fragments of NPC cells which contained numerous large vesicles filled with an amorphous material and surrounded by abundant tubular structures. These vesicles and their content as well as their close surroundings were heavily decorated with gold particles attributed to GST-PFO (Figure 8A,B, arrows point to accumulations of $6 \mathrm{~nm}$ gold particles). On this basis the electron-opaque content of the vesicles can be ascribed to cholesterol deposits. However, a fraction of cholesterol was probably removed due to harsh conditions used for dehydration and embedding of cells in the resin leaving the interior of some of the lysosomes translucent. The GST-PFO-decorated vesicles were also moderately labeled with anti-LAMP-1 antibody which mainly stained the borders of the structures (Figure 8A, semicircles indicate 

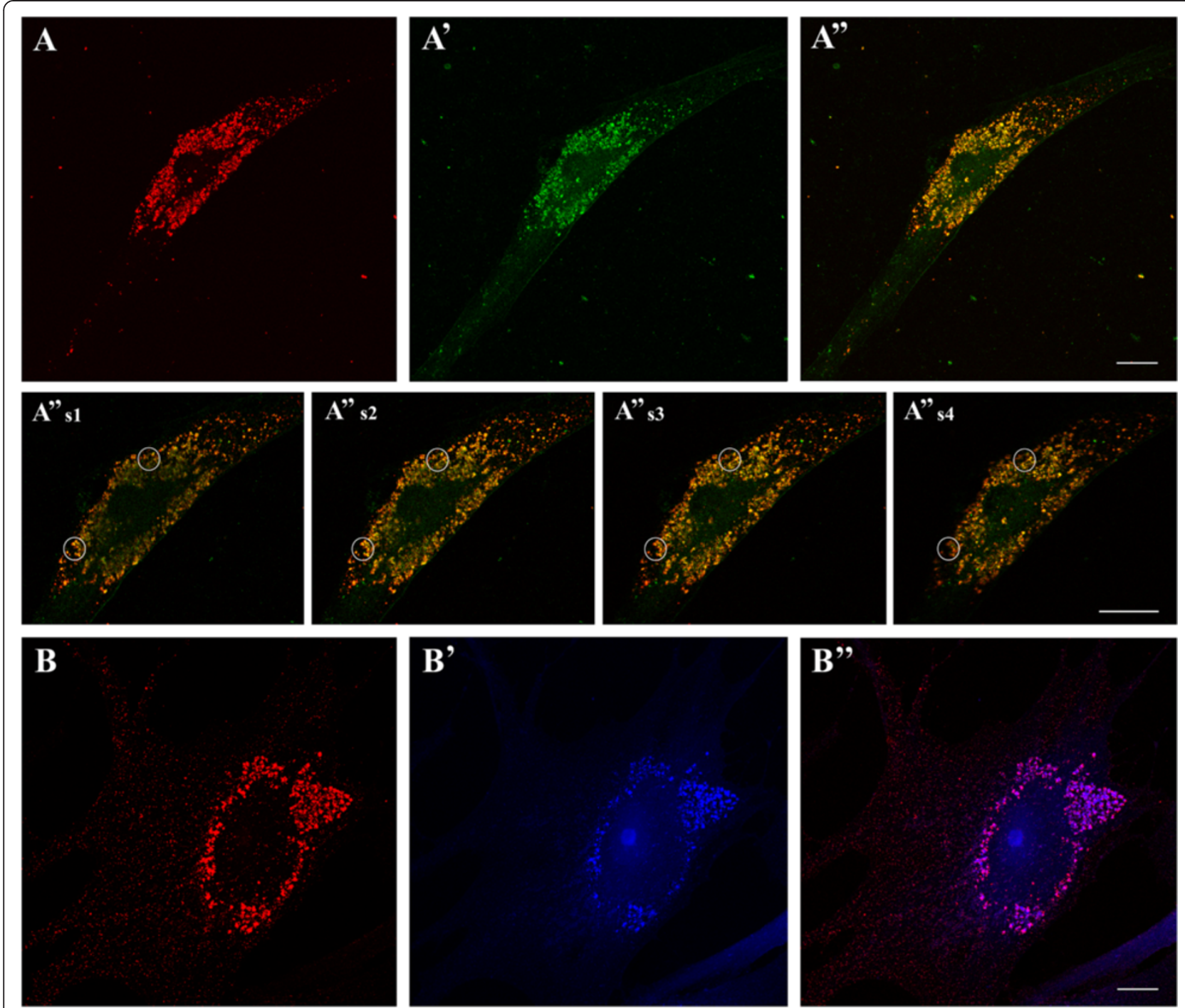

Figure 4 Colocalization of GST-PFO with LAMP-1 and filipin in NPC fibroblasts. Cholesterol visualized by GST-PFO (red) is present in lysosomes identified by anti-LAMP-1 (green in $\mathbf{A}^{\prime}-\mathbf{A}^{\prime \prime}$ ) and filipin (blue in $\mathbf{B}^{\prime}-\mathbf{B}^{\prime \prime}$ ). ( $\mathbf{A}^{\prime \prime} \mathbf{s}$ 1-s4) Merged images of optical sections of the cell shown in $\left(\mathbf{A}-\mathbf{A}^{\prime \prime}\right)$. The sections range from the basolateral $\left(\mathbf{A}^{\prime \prime} \mathbf{s} 1\right)$ to the apical $\left(\mathbf{A}^{\prime \prime} \mathbf{s} 4\right)$ part of the cell. $\left(\mathbf{A}^{\prime \prime}, \mathbf{B}^{\prime \prime}\right)$ Merged images of $\left(\mathbf{A}-\mathbf{A}^{\prime}\right)$ and $\left(\mathbf{B}^{-} \mathbf{B}^{\prime}\right)$, respectively. Colocalization of GST-PFO and LAMP-1 is seen as yellow color in (A" and A"s1-s4) while pink color reflects colocalization of GST-PFO- and filipin-positive structures in $\left(\mathbf{B}^{\prime \prime}\right)$. Scale bars, $20 \mu \mathrm{m}$.

$10 \mathrm{~nm}$ gold particles). This pattern of staining with GSTPFO and anti-LAMP-1 antibody was characteristic to NPC cells. Ultrathin sections of control healthy fibroblasts were devoid of large vesicles and were only scarcely labeled with GST-PFO. LAMP-1-decorating gold particles were found as singlets and small clusters located mainly at the borders of small vesicles (Figure $8 \mathrm{C}$, semicircles).

\section{Application of GST-PFO for cholesterol determination in} NPC cells by cellular ELISA

The presence of the GST tag in the fusion protein allowed us to estimate the level of free cholesterol in cells by cellular ELISA. The signal generated by GST-PFO/ anti-GST IgY-peroxidase increased in a linear manner with the number of cells, from $1 \times 10^{3}$ to $15 \times 10^{3}$ cells/ well (Figure 9A).

To examine whether Triton X-100 used for permeabilization of cells prior to GST-PFO labeling can extract cholesterol from the deposits, fixed NPC cells were exposed to the detergent in the concentration range from $0.03 \%$ to $0.2 \%$. Treatment of cells with $0.05-0.2 \%$ Triton $\mathrm{X}-100$ did not significantly affect cholesterol detection by GST-PFO (Figure 9B), indicating that cholesterol deposits in NPC cells are resistant to extraction with these concentrations of detergent. In cells permeabilized with $0.03 \%$ Triton X-100 the amounts of cholesterol detected by GST-PFO were slightly lower in comparison to these revealed at $0.05-0.2 \%$ Triton X-100 (Figure 9B), 

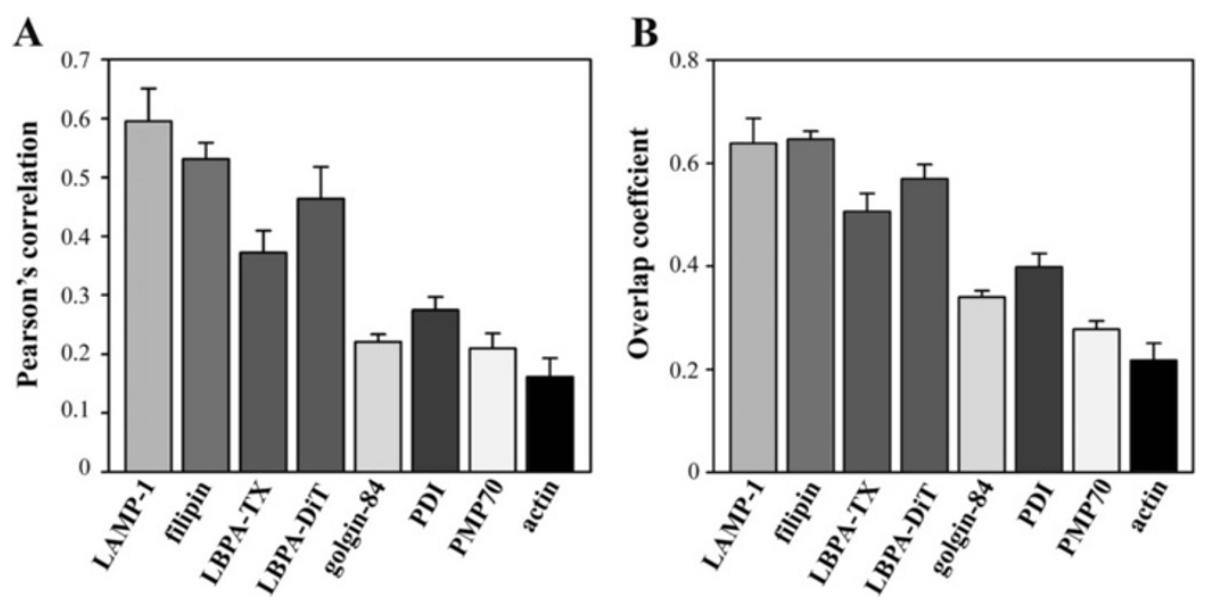

Figure 5 Quantitation of colocalization of GST-PFO-positive structures and other cellular components in NPC fibroblasts. (A) Pearson's correlation coefficient, (B) overlap coefficient for co-immunostaining with GST-PFO and filipin or antibodies against LAMP1, LBPA, golgin-84, PDI, PMP70 or phalloidin used as an actin filament marker. TX, Triton X-100, DiT, digitonin. Data shown are mean \pm SEM.

suggesting that in these condition the access of the probe to cholesterol deposits could be limited. Finally, GST-PFO failed to label NPC cells that were not permeabilized (Figure 9D). Therefore, permeabilization of cells with Triton $\mathrm{X}-100$ is required for the probe to gain access to the cholesterol deposits in cells. This is in contrast to filipin which stained cholesterol in non-permeabilized cells (Figure 9D'-D"). Moreover, after treatment of cells with $0.05 \%$ Triton X-100, cholesterol deposits became sensitive to extraction with $3 \mathrm{mM}$ methyl- $\beta$-cyclodextrin which reduced subsequent GST-PFO binding by over $80 \%$ (Figure 9B). The data indicate that permeabilization of the plasma membrane and membranes of the intracellular vesicles ensures high efficiency of cholesterol removal from intracellular stores by methyl- $\beta$-cyclodextrin. In contrast to Triton X-100, permeabilization of cells with $0.05 \%$ digitonin gave unsatisfactory results since it reduced GSTPFO binding by about $50 \%$ (Figure 9B).

Using the cellular ELISA based on GST-PFO binding to Triton X-100-permeabilized cells we compared cholesterol levels in fibroblasts from NPC patients and a healthy control. The level of free cholesterol in cells from two patients was fairly similar and was 2-2.4-fold higher than in control fibroblasts (Figure 9C). Consistent with earlier results, exposure of Triton X-100-permeabilized cells to $3 \mathrm{mM}$ methyl- $\beta$-cyclodextrin reduced the amount of cholesterol by about $85 \%$ in both normal and NPC cells (Figure 9C).

To estimate feasibility of using GSTO-PFO to distinguish between different biochemical phenotypes of NPC cells, the results of PFO-based cellular ELISA were compared with the results of routine filipin staining of cells derived from various NPC patients. Cells obtained from three persons (patients 1-3) unambiguously diagnosed as NPC patients based on clinical symptoms and strong filipin staining of fibroblasts displayed also strong GSTPFO binding in cellular ELISA (Table 1). In addition, the same analysis revealed relatively intense filipin and GST-PFO staining of another fibroblast line (patient 4), despite it was derived from a person whose preliminary NPC diagnosis was not confirmed by genetic testing (Table 1). Of interest, GST-PFO allowed to detect a moderate increase of the free cholesterol level in fibroblasts from a person who was preliminarily classified as a NPC patient based on a weak filipin staining and mild clinical symptoms (patient 5) and the diagnosis was later confirmed by a genetic approach (Table 1). Taken together, the data indicate that GST-PFO can be as useful as filipin in detection of free cholesterol deposits in NPC cells. In comparison, two other potential NPC diagnostic methods, the measurement of total cholesterol content in fibroblasts as well as the chitotriosidase activity in serum of NPC patients yielded much less conclusive results. In general, the total cellular cholesterol content in cells and the chitotriosidase activity in serum were elevated in NPC patients but these parameters did not correlate with the accumulation of free cholesterol in cells or the severity of NPC clinical symptoms (Table 1). This is in agreement with earlier findings that the chitotriosidase activity can change with the age of NPC patients and abnormal activity of the enzyme can be found also in lysosomal storage disorders other than NPC $[19,45]$. On the other hand, defects in cholesterol esterification, typical for NPC disease, can account for the discrepancies between the total cholesterol level and the accumulation of free cholesterol in NPC cells $[39,46]$.

\section{Discussion}

Mutations in the NPC1 and NCP2 genes disturb the trafficking of cholesterol in cells. These mutations are 


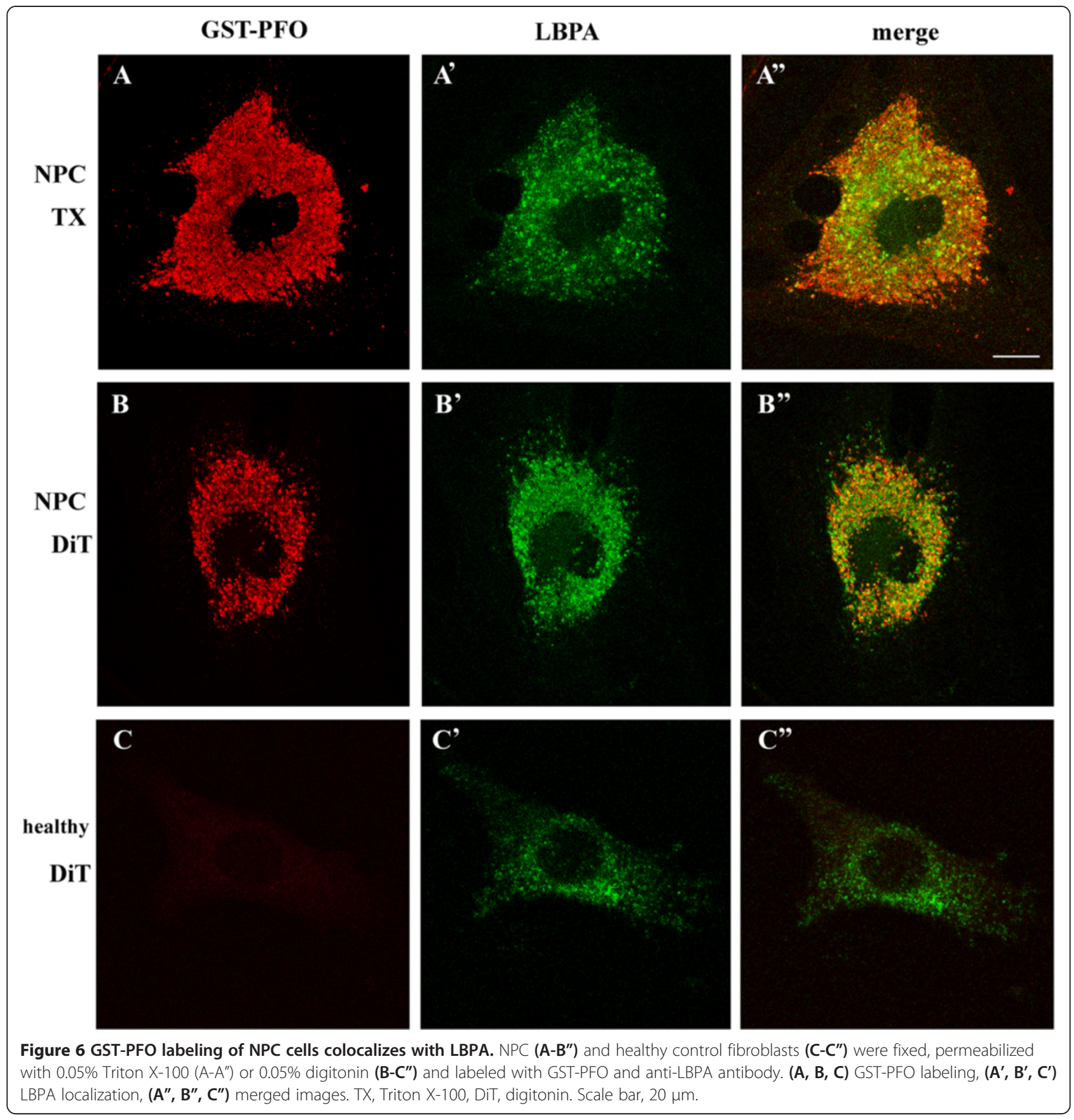

linked to a wide clinical spectrum of NPC disease and their diversity seems to contribute to the heterogeneity of NPC symptoms that range from severe to mild neurological defects, organomegaly and psychiatric symptoms $[3,14]$. At the cellular level the abnormalities in cholesterol trafficking are manifested by accumulation of free unesterified cholesterol and disturbance in the metabolism of some other lipids, particularly sphingolipids $[6,12,47]$. At present, cholesterol deposits in NPC cells are detected by staining of cells derived from skin biopsies with the polyene antibiotic filipin [3,16,39].
In this report we demonstrate that cholesterol deposits in fibroblasts from NPC patients can be conveniently visualized using a recombinant bacterial toxin, perfringolysin O fused with a GST tag. GST-PFO stained cholesterol in late endosomes/lysosomes in NPC fibroblasts permeabilized with $0.05 \%$ Triton X-100.

GST-PFO can easily be produced in large quantities in E. coli and purified by simple one-step column affinity chromatography. The probe is highly selective for cholesterol, as we demonstrated by protein-lipid overlay assay and surface plasmon resonance analysis. The recombinant 

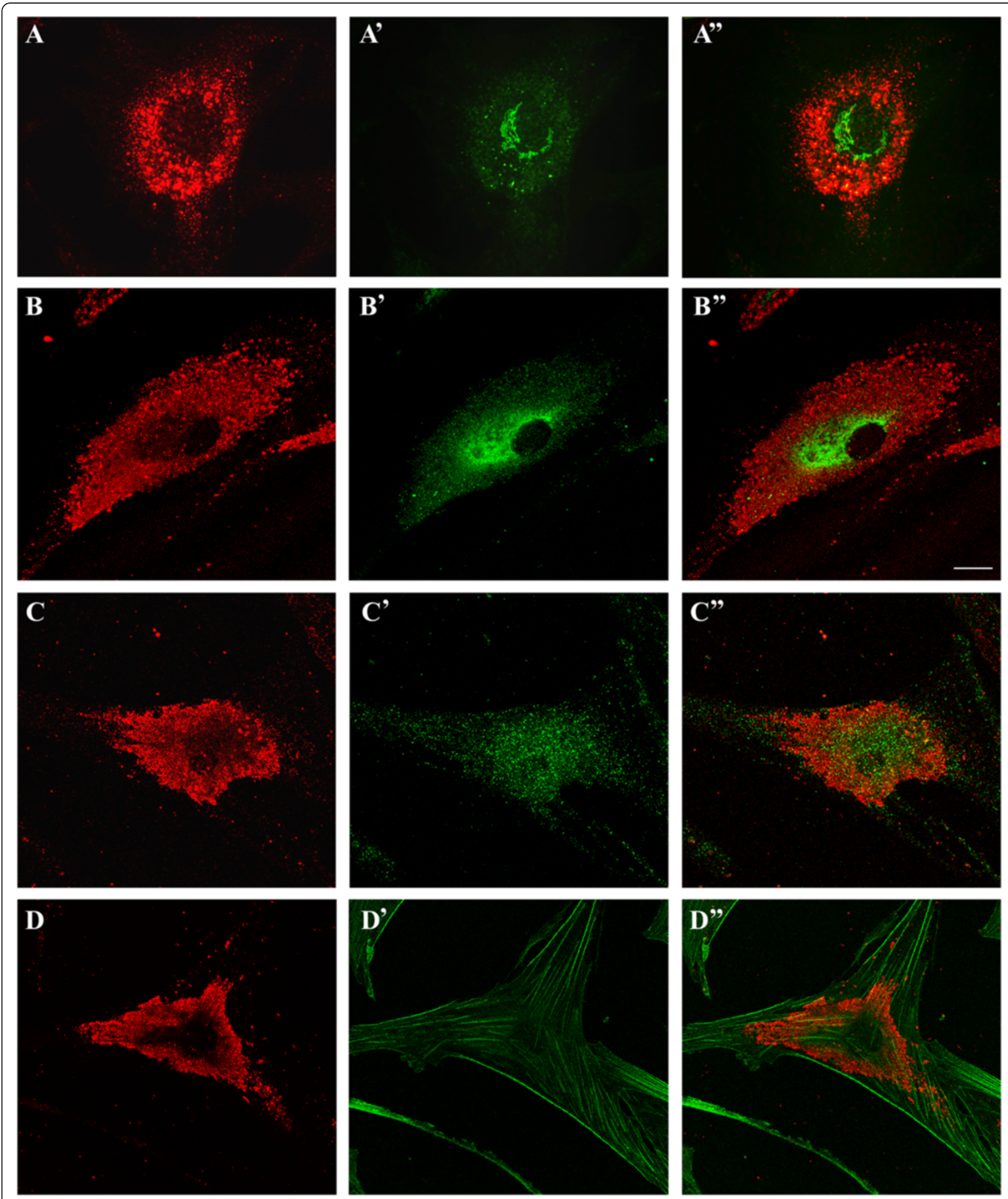

Figure 7 Negligible co-immunostaining of GST-PFO-positive structures and other organelles in NPC cells. (A-D) Distribution of GST-PFO-

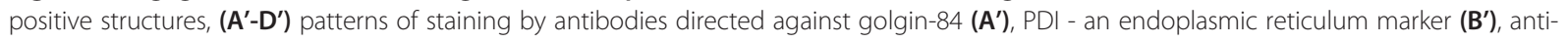
PMP70 - a peroxisomal marker $\left(\mathbf{C}^{\prime}\right)$ and phalloidin labeling actin filaments $\left(\mathbf{D}^{\prime}\right)$. ( $\left.\mathbf{A}^{\prime \prime}-\mathbf{D}^{\prime \prime}\right)$ merging of the corresponding pairs of images displays traces of the yellow color indicating different localization of GST-PFO-positive structures and the examined proteins. Scale bar, $20 \mu \mathrm{m}$. 

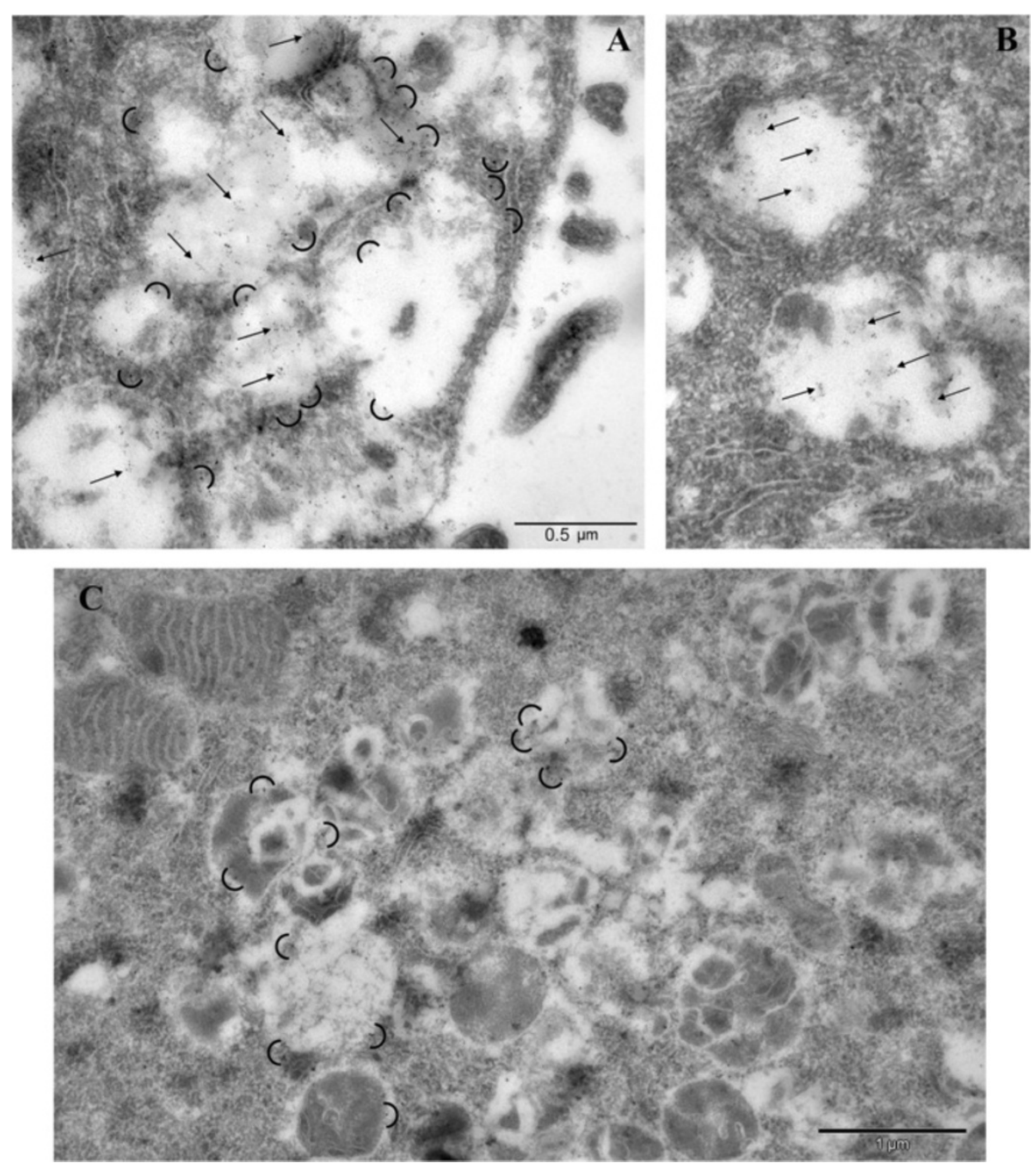

Figure 8 Immunoelectron microscopy analysis of GST-PFO staining in NPC and healthy fibroblasts. Ultrathin sections of NPC cells (A, B) or control healthy fibroblasts (C) were subjected to post-embedding immunogold labeling with GST-PFO followed by anti-GST-biotin and antibiotin-gold antibodies $(6 \mathrm{~nm})$ together with rabbit anti-LAMP-1 and anti-rabbit-gold antibodies $(10 \mathrm{~nm})$. GST-PFO decorates material accumulated in vesicles of NPC cells (arrows in A, B) while LAMP-1 is visualized mainly at the borders of vesicles in NPC and control fibroblasts (semicircles in A and $\mathbf{C}$ ).

protein preserves the lytic activity of the native toxin and causes an efflux of 6-carboxyfluorescein from cholesterolcontaining liposomes, but not from those devoid of cholesterol (Figure 1B). PFO binds to membranes and causes their permeabilization when the cholesterol content exceeds $30 \mathrm{~mol} \%[25,26]$. Therefore, the deposits of cholesterol in NPC cells make them preferable targets of GST-PFO. On the other hand, even though free cholesterol is present in non-NPC cells as well, its level is too low to lead to any marked staining by GST-PFO. The lytic activity of PFO does not affect the staining of cells which were fixed before the treatment with the probe. The presence of the GST tag allows detection of the probe bound to cholesterol in NPC cells with a wide array of anti-GST antibodies. Depending on the label conjugated with the anti-GST antibody various detection techniques can be used. In our hands, the probe allowed unequivocal detection of cholesterol deposits in cells by immunofluorescence and immunoelectron microscopy, and by cellular ELISA. The latter approach is suitable for screening a large number of samples and offers the possibility of a semiquantitative analysis of free cholesterol accumulated in cells. Cellular ELISA based on GST-PFO binding to cells seems to be able to distinguish and quantify "variant" biochemical phenotypes of NPC cells showing the level of cholesterol accumulation in the cells. Our preliminary data show that the GST-PFO probe is also suitable for detection of free cholesterol by FACS analysis (not shown). 


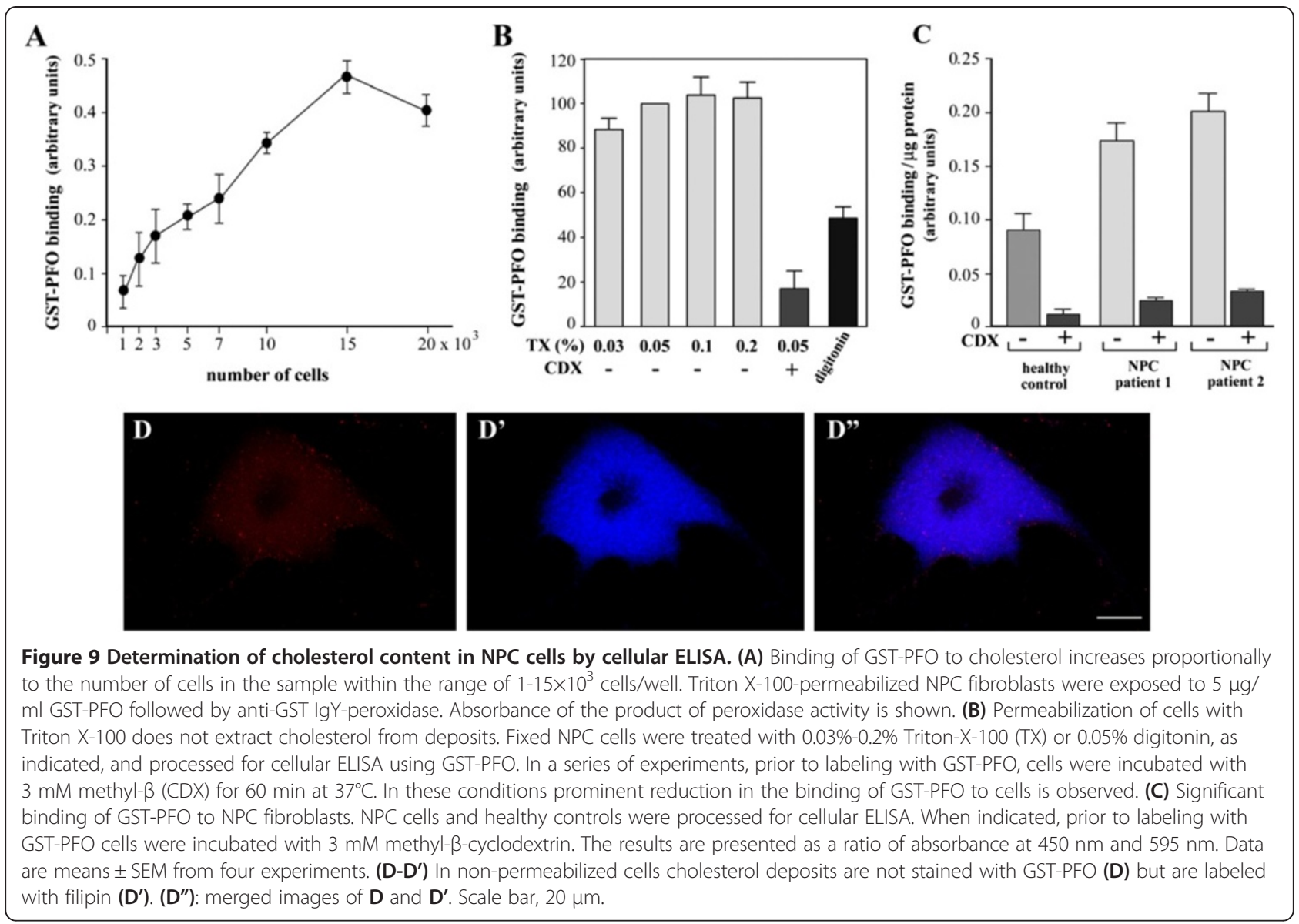

The fluorescence technique is routinely used for visualization of free cholesterol deposits in NPC cells by filipin $[3,41]$. Having a high affinity toward cholesterol, filipin forms fluorescent complexes with the lipid [17]. However, the use of filipin has some drawbacks compared to GST-PFO. The fluorescence of filipin requires UV excitation, is easily scattered, and undergoes rapid photobleaching [18]. The use of GST-PFO for labeling does not pose such constraints, the probe can be detected in a wide range of visible or infrared wavelengths, and the fluorochromes available are fairly stable. Owing to these properties, GST-PFO also facilitates studies on the nature of vesicles harboring cholesterol deposits in NPC cells, which is another advantage of GST-PFO over filipin.

In 2003-2004 Chang's group made an attempt to use a PFO derivative for cholesterol detection in NPC cells. The so-called $\mathrm{BC} \theta$ probe was obtained by proteolytic digestion of PFO and biotinylation of the complex of the two resulting fragments [48]. This probe was used to stain a Chinese hamster ovary cell line lacking the NPC1 protein, fibroblasts of NPC patients, and sections of

Table 1 Comparisons of different methods used in NPC disease diagnosis

\begin{tabular}{cccccc}
\hline Patients & $\begin{array}{c}\text { GST-PFO cellular ELISA } \\
\text { (arbitrary units) }\end{array}$ & $\begin{array}{c}\text { Filipin } \\
\text { staining }\end{array}$ & $\begin{array}{c}\text { Total cholesterol } \\
\text { content }(\boldsymbol{\mu g} / \mathbf{m l})\end{array}$ & $\begin{array}{c}\text { Chitotriosidase activity } \\
(\mathbf{n m o l} / \mathbf{m l} / \mathbf{h})\end{array}$ & Comments \\
\hline 1 & $0.205 \pm 0.031$ & +++ & $115.72 \pm 6.06$ & $1515-1810$ & Typical symptoms \\
2 & $0.192 \pm 0.042$ & +++ & $\mathrm{ND}$ & $465-783$ & Typical symptoms \\
3 & $0.181 \pm 0.024$ & +++ & $87.21 \pm 14.80$ & 212 & Typical symptoms \\
4 & $0.166 \pm 0.036$ & ++ & $53.86 \pm 5.41$ & $\mathrm{ND}$ & Qualified initially as NPC, not confirmed genetically \\
5 & $0.130 \pm 0.018$ & + & $58.08 \pm 11.91$ & $286-323$ & Moderate symptoms - progressing with age, \\
genetically confirmed
\end{tabular}


brains of NPC mice. The authors showed that $\mathrm{BC} \theta$ stained mainly "cholesterol-rich domains" inside the cells $[27,28]$. The probe entered the cell without prior permeabilization with detergents. Instead, it was shown that the cells became permeable to $\mathrm{BC} \theta$ when fixed with $4 \%$ paraformaldehyde. This approach is unusual, especially taking into account the relatively high molecular mass of BC $\theta$ (ca. $57 \mathrm{kDa}$ ) and streptavidin-Texas Red (forms tetramers of ca. $76 \mathrm{kDa}$ ) used for analysis. In these conditions, both the entry of proteins across the plasma membrane, and particularly across the endosomal/lysosomal membrane and washout of excess protein, are impeded. Perhaps for these reasons the $\mathrm{BC} \theta$-positive structures were not well distinguished. In our studies, beside fixation, the cells were additionally permeabilized with $0.05 \%$ Triton X-100. Omitting the detergent treatment excluded any labeling of the cells with GST-PFO (ca. $78 \mathrm{kDa}$ ). On the other hand, 0.05\%02\% Triton X-100 did not solubilize the cholesterol deposits in NPC cells, judging from the intense filipin and GST-PFO staining and cellular ELISA analysis. Permeabilization of cells with Triton X-100 increased the accessibility of cholesterol deposits to GST-PFO. Cholesterol deposits were also freely accessible to methyl- $\beta$ cyclodextrin which significantly reduced their level in the cells. This effect was not achieved in non-permeabilized cells exposed to cyclodextrin after fixation with $4 \%$ paraformaldehyde [24]. Using permeabilized cells we were able to reveal that vesicles labeled by GST-PFO were also positive for LAMP-1 and LBPA. LAMP-1 is generally accepted as a marker of lysosomes [49] while LBPA accumulates in the inner membranes of multivesicular bodies [43]. In contrast to earlier reports on a high degree of colocalization of filipin-stained vesicles with LBPA [44] in our hands vesicles labeled by GST-PFO displayed significant but not complete overlapping with LBPA staining. This could ensue from technical problems of cell permeabilization which is hard to optimize for both lipids and possibly also from the fact that we work on cells cultured for $72 \mathrm{~h}$ in delipidated FBS, which could affect cellular distribution of LBPA. Our data indicate that GST-PFO-positive structures bear markers of late endosomes/lysosomes but not those of endoplasmic reticulum, Golgi apparatus or peroxisomes.

Altogether, the data indicate that GST-PFO is a convenient and reliable probe for detection of cholesterol deposits in cells of NPC patients.

\section{Abbreviations}

BC $\theta$ : Biotinylated derivative of perfringolysin O; DOPC:

Dioleoylphosphatidylcholine; DPPC: Dipalmitoylphosphatidylcholine; DPPE: Dipalmitoylphosphatidylethanolamine; GST: Glutathione transferase; LAMP-1: Lysosomal-associated membrane protein 1; LBPA: Lysobisphosphatidic acid; LDL: Low density lipoprotein; NPC: Niemann-Pick type C; PDI: Protein disulfide isomerase; PFO: Perfringolysin O; PMP70: Peroxisomal membrane protein of $70 \mathrm{kDa}$; SM: Sphingomyelin; TEV: Tobacco Etch virus.

\section{Competing interests}

The authors declare that they have no competing interests.

\section{Authors' contributions}

KK performed confocal and electron microscopy studies, colocalization analysis, participated in drafting and editing the manuscript; EM-S initiated and performed a part of (immuno) fluorescence studies, established conditions for GST-PFO staining of cells; GT and PK cloned GST-PFO and purified the protein, GT also performed cellular ELISA studies; MM and At carried out diagnostics of NPC patients, provided primary cultures of fibroblasts, guided in filipin staining of the cells; MK performed in vitro studies on binding of GST-PFO to cholesterol; AG contributed to studies on LBPA; AS conceived and designed the experiments, analyzed the data, contributed to manuscript writing. All authors read and approved the final manuscript.

\section{Acknowledgements}

This work was supported by grant N N401 557040 from the National Science Center, Poland.

We thank the staff of the Laboratory of Imaging Tissues Structure and Function and the Laboratory of Electron Microscopy at the Nencki Institute for the assistance.

\section{Author details}

${ }^{1}$ Department of Cell Biology, Nencki Institute of Experimental Biology, 3 Pasteur St., 02-093 Warsaw, Poland. '2Department of Genetics, Institute of Psychiatry and Neurology, 9 Sobieskiego St., 02-957 Warsaw, Poland. ${ }^{3}$ Institute of Biochemistry and Biophysics, 5a Pawinskiego St., 02-106 Warsaw, Poland.

Received: 30 October 2013 Accepted: 16 April 2014

Published: 28 April 2014

\section{References}

1. Pentchev PG, Vanier MT, Suzuki K, Patterson M: Niemann-Pick disease type C: a cellular cholesterol lipidosis. In The Metabolic and Molecular Bases of Inherited Disease. Edited by Scriver CR, Beaudet AL, Sly WS, Valle D. New York: McGraw Hill; 1995:2625-2639.

2. Reid PC, Sugii S, Chang TY: Trafficking defects in endogenously synthesized cholesterol in fibroblasts, macrophages, hepatocytes, and glial cells from Niemann-Pick type C1 mice. J Lipid Res 2003, 44:1010-1019.

3. Vanier MT, Millat G: Niemann-Pick disease type C. Clin Genet 2003, 64:269-281.

4. Vanier MT: Niemann-Pick disease type C. Orphanet J Rare Dis 2010, 5:16

5. Goldstein JL, Brown MS: The LDL receptor. Arterioscler Thromb Vasc Biol 2009, 29:431-438.

6. Blanchette-Mackie EJ: Intracellular cholesterol trafficking: role of the NPC1 protein. Biochim Biophys Acta 2000, 1486:171-183.

7. Patterson MC, Vanier MT, Suzuki K, Morris JA, Carstea ED, Neufeld EB, Blanchette-Mackie EJ, Pentchev PG: Niemann-Pick disease type C: a lipid trafficking disorder. In The Metabolic and Molecular Bases of Inherited Disease. Edited by Scriver CR, Beaudet AL, Sly WS, Valle D, Child B, Kinzler KW, Vogelstein B. New York: McGraw-Hill; 2001:3611-3634.

8. Vanier MT, Duthel S, Rodriguez-Lafrasse C, Pentchev P, Carstea ED: Genetic heterogeneity in Niemann-Pick $C$ disease: a study using somatic cell hybridization and linkage analysis. Am J Hum Genet 1996, 58:118-125.

9. Carstea ED, Morris JA, Coleman KG, Loftus SK, Zhang D, Cummings C, Gu J, Rosenfeld MA, Pavan WJ, Krizman DB, Nagle J, Polymeropoulos MH, Sturley SL, loannou YA, Higgins ME, Comly M, Cooney A, Brown A, Kaneski CR, Blanchette-Mackie EJ, Dwyer NK, Neufeld EB, Chang TY, Liscum L, Strauss JF III, Ohno K, Zeigler M, Carmi R, Sokol J, Markie D, et al: Niemann-Pick C1 disease gene: homology to mediators of cholesterol homeostasis. Science 1997, 277:228-231.

10. Friedland N, Liou HL, Lobel P, Stock AM: Structure of a cholesterol-binding protein deficient in Niemann-Pick type C2 disease. Proc Natl Acad Sci U S A 2003, 100:2512-2517.

11. Scott C, loannou YA: The NPC1 protein: structure implies function. Biochim Biophys Acta 2004, 1685:8-13.

12. Sun $X$, Marks DL, Park WD, Wheatley $C L$, Vishwajeet $P$, O'Brien JF, Kraft DL, Lundquist PA, Patterson MC, Pagano RE, Snow K: Niemann-Pick C variant detection by altered sphingolipid trafficking and correlation with 
mutations within a specific domain of NPC1. Am J Hum Genet 2001, 68:1361-1372

13. Zervas M, Somers KL, Thrall MA, Walkley SU: Critical role for glycosphingolipids in Niemann-Pick disease type C. Curr Biol 2001, 11:1283-1287

14. Patterson MC, Mengel E, Wijburg FA, Muller A, Schwierin B, Drevon $H$, Vanier MT, Pineda M: Disease and patient characteristics in NP-C patients: findings from an international disease registry. Orphanet J Rare Dis 2013, 8:12.

15. Patterson MC, Vecchio D, Prady H, Abel L, Wraith JE: Miglustat for treatment of Niemann-Pick $C$ disease: a randomised controlled study. Lancet Neurol 2007, 6:765-772.

16. Patterson MC, Hendriksz CJ, Walterfang M, Sedel F, Vanier MT, Wijburg F: Recommendations for the diagnosis and management of Niemann-Pick disease type C: an update. Mol Genet Metab 2012, 106:330-344.

17. Gimpl G: Cholesterol-Protein Interaction: Methods and Cholesterol Reporter Molecules. In Cholesterol Binding and Cholesterol Binding Proteins. Structure and Function in Health and Disease. Edited by Harris JR. Dordrecht Netherlands: Springer Science+Business media BV; 2010:1-46.

18. Boutté $Y$, Men S, Grebe M: Fluorescent in situ visualization of sterols in Arabidopsis roots. Nature Protoc 2011, 6:446-456.

19. Wraith JE, Baumgartner MR, Bembi B, Covanis A, Levade T, Mengel T, Pineda M, Sedel F, Topçu M, Vanier MT, Widner H, Wijburg FA, Patterson MC: Recommendations on the diagnosis and management of Niemann-Pick disease type C. Mol Genet Metab 2009, 98:152-165.

20. Jiang X, Sidhu R, Porter FD, Yanjanin NM, Speak AO, te Vruchte DT, Platt FM, Fujiwara H, Scherrer DE, Zhang J, Dietzen DJ, Schaffer JE, Ory DS: A sensitive and specific LC-MS/MS method for rapid diagnosis of Niemann-Pick C1 disease from human plasma. J Lipid Res 2011, 52:1435-1445.

21. Rossjohn J, Feil SC, McKinstry WJ, Tweten RK, Parker MW: Structure of a cholesterol-binding, thiol-activated cytolysin and a model of its membrane form. Cell 1997, 89:685-692.

22. Tweten RK, Parker MW, Johnson AE: The cholesterol-dependent cytolysins. Curr Top Microbiol Immunol 2001, 257:15-33.

23. Shepard LA, Heuck AP, Hamman BD, Rossjohn J, Parker MW, Ryan KR, Johnson AE, Tweten RK: Identification of a membrane-spanning domain of the thiol-activated pore-forming toxin Clostridium perfringens perfringolysin O: an a-helical to $\beta$-sheet transition identified by fluorescence spectroscopy. Biochemistry 1998, 37:14563-14574.

24. Ohno-Iwashita Y, Shimada Y, Hayashi M, Iwamoto M, Iwashita S, Inomata M: Cholesterol-binding toxins and anti-cholesterol antibodies as structural probes for cholesterol localization. Subcell Biochem 2010, 51:597-621.

25. Ohno-Iwashita Y, Shimada Y, Waheed AA, Hayashi M, Inomata M, Nakamura M, Maruya M, Iwashita S: Perfringolysin O, a cholesterol-binding cytolysin, as a probe for lipid rafts. Anaerobe 2004, 10:125-134.

26. Flanagan JJ, Tweten RK, Johnson AE, Heuck AP: Cholesterol exposure at the membrane surface is necessary and sufficient to trigger perfringolysin O binding. Biochemistry 2009, 48:3977-3987.

27. Sugii S, Reid PC, Ohgami N, Shimada Y, Maue RA, Ninomiya H, Ohno-Iwashita $Y$, Chang TY: Biotinylated $\theta$-toxin derivative as a probe to examine intracellular cholesterol-rich domains in normal and Niemann-Pick type C1 cells. J Lipid Res 2003, 44:1033-1041.

28. Reid PC, Sakashita N, Sugii S, Ohno-Iwashita Y, Shimada Y, Hickey WF, Chang TY: A novel cholesterol stain reveals early neuronal cholesterol accumulation in the Niemann-Pick type C1 mouse brain. J Lipid Res 2004, 45:582-591

29. Ługowska A, Musielak M: Diagnostics of Niemann-Pick type $C$ disease. Klinika Pediatryczna - Neurometabolizm (in Polish) 2013, 21:68-71.

30. Cham BE, Knowles BR: A solvent system for delipidation of plasma or serum without protein precipitation. J Lipid Res 1976, 17:176-181.

31. Kapust RB, Tözsér J, Fox JD, Anderson DE, Cherry S, Copeland TD, Waugh DS: Tobacco etch virus protease: mechanism of autolysis and rational design of stable mutants with wild-type catalytic proficiency. Protein Eng 2001, 14:993-1000

32. Kulma M, Hereć M, Grudziński W, Anderluh G, Gruszecki WI, Kwiatkowska K, Sobota A: Sphingomyelin-rich domains are sites of lysenin oligomerization: implications for raft studies. Biochim Biophys Acta 2010, 1798:471-481.

33. Kwiatkowska K, Hordejuk R, Szymczyk P, Kulma M, Abdel-Shakor AB, Plucienniczak A, Dolowy K, Szewczyk A, Sobota A: Lysenin, a sphingomyelin-binding toxin, forms cation-selective channels in planar lipid bilayers. Mol Membr Biol 2007, 24:121-134.

34. Taki T, Ishikawa D: TLC blotting: application to microscale analysis of lipids and as a new approach to lipid-protein interaction. Anal Biochem 1997, 251:135-143.

35. Hollak CE, van Weely S, van Oers MH, Aerts JM: Marked elevation of plasma chitotriosidase activity A novel hallmark of Gaucher disease. J Clin Invest 1994, 93:1288-1292.

36. Kwiatkowska K, Frey J, Sobota A: Phosphorylation of FcyRIIA is required for the receptor-induced actin rearrangement and capping: the role of membrane rafts. J Cell Sci 2003, 116:537-550.

37. Hotze EM, Tweten RK: Membrane assembly of the cholesterol-dependent cytolysin pore complex. Biochim Biophys Acta 1818, 2012:1028-1038.

38. Nelson GJ: Studies on the lipids of sheep red blood cells. I. Lipid composition in low and high potassium red cells. Lipids 1967, 2:64-71.

39. Pentchev PG, Comly ME, Kruth HS, Vanier MT, Wenger DA, Patel S, Brady RO: A defect in cholesterol esterification in Niemann-Pick disease (type C) patients. Proc Natl Acad Sci U S A 1985, 82:8247-8251.

40. Pipalia NH, Huang A, Ralph H, Rujoi M, Maxfield FR: Automated microscopy screening for compounds that partially revert cholesterol accumulation in Niemann-Pick C cells. J Lipid Res 2006, 47:284-301.

41. Tängemo C, Weber D, Theiss S, Mengel E, Runz H: Niemann-Pick Type C disease: characterizing lipid levels in patients with variant lysosomal cholesterol storage. J Lipid Res 2011, 52:813-825.

42. Manders EMM, Verbeek FJ, Aten JA: Measurement of co-localization of objects in dual-colour confocal images. J Microscopy 1993, 169:375-382.

43. Kobayashi T, Stang E, Fang KS, de Moerloose P, Parton RG, Gruenberg J: A lipid associated with the antiphospholipid syndrome regulates endosome structure and function. Nature 1998, 392:193-197.

44. Kobayashi T, Beuchat MH, Lindsay M, Frias S, Palmiter RD, Sakuraba H, Parton RG, Gruenberg J: Late endosomal membranes rich in lysobisphosphatidic acid regulate cholesterol transport. Nat Cell Biol 1999, 1:113-118.

45. Ries M, Schaefer E, Lührs T, Mani L, Kuhn J, Vanier MT, Krummenauer F, Gal A, Beck M, Mengel E: Critical assessment of chitotriosidase analysis in the rational laboratory diagnosis of children with Gaucher disease and Niemann-Pick disease type A/B and C. J Inherit Metab Dis 2006, 29:647-652

46. Harzer K, Kustermann-Kuhn B: Quantified increases of cholesterol, total lipid and globotriaosylceramide in filipin-positive Niemann-Pick type C fibroblasts. Clin Chim Acta 2001, 305:65-73.

47. Salvioli R, Scarpa S, Ciaffoni F, Tatti M, Ramoni C, Vanier MT, Vaccaro AM: Glucosylceramidase mass and subcellular localization are modulated by cholesterol in Niemann-Pick disease type C. J Biol Chem 2004, 279:17674-17680.

48. Shimada Y, Maruya M, Iwashita S, Ohno-Iwashita Y: The C-terminal domain of perfringolysin $\mathrm{O}$ is an essential cholesterol-binding unit targeting to cholesterol-rich microdomains. Eur J Biochem 2002, 269:6195-6203.

49. Andrejewski N, Punnonen EL, Guhde G, Tanaka Y, Lüllmann-Rauch R, Hartmann D, von Figura K, Saftig P: Normal lysosomal morphology and function in LAMP-1-deficient mice. J Biol Chem 1999, 274:12692-12701.

\section{doi:10.1186/1750-1172-9-64}

Cite this article as: Kwiatkowska et al.: Visualization of cholestero deposits in lysosomes of Niemann-Pick type C fibroblasts using recombinant perfringolysin 0 . Orphanet Journal of Rare Diseases 2014 9:64. 